\title{
The effect of different doses of flumazenil on acetaminophen toxicity in rats
}

\author{
Bozogluer E ${ }^{1}$, Madenoglu $\mathrm{H}^{1}$, Aksu R ${ }^{1}$, Bicer $\mathrm{C}^{1}$, Yazici $\mathrm{C}^{2}$, Boyaci $\mathrm{A}^{1}$ \\ Department of Anesthesiology, Erciyes University Medical Faculty, Kayseri, Turkey. raksu@erciyes.edu.tr
}

\begin{abstract}
Background: Acetaminophen is an analgesic drug that is used safely in therapeutic doses. At high doses, it causes hepatotoxicity, resulting in hepatic necrosis. Some medications and methods are available for treatment of acetaminophen overdose. However, results are inconsistent, and sufficient outcomes cannot always be obtained.

Objective: The mechanism of action of acetaminophen has not been fully understood. It has been suggested that it exerts its effects on GABA receptors. Flumazenil has been experimentally proven to produce an antagonism on acetaminophen's analgesic effect.

The purpose of this study was to determine whether flumazenil antagonized the toxic effects of acetaminophen overdose in rats.

Methods: A total of 49 Wistar albino rats weighing between $250-350 \mathrm{~g}$ were used in the study. Nine rats were examined for a preliminary study, and the other rats were randomly divided into five groups with eight subjects in each. Control group: Saline; Acetaminophen group: $3 \mathrm{~g} / \mathrm{kg}$ acetaminophen; Experimental Group F1: $3 \mathrm{~g} / \mathrm{kg}$ acetaminophen $+0.1 \mathrm{mg} / \mathrm{kg}$ flumazenil; Experimental group F2: $3 \mathrm{~g} / \mathrm{kg}$ acetaminophen $+1 \mathrm{mg} / \mathrm{kg}$ flumazenil; Experimental group F3: $3 \mathrm{~g} / \mathrm{kg}$ acetaminophen $+10 \mathrm{mg} / \mathrm{kg}$ flumazenil. Acetaminophen was administered in a $3 \mathrm{ml}$ saline solution by way of gastric catheter. Flumazenil was administered by way of intraperitoneal injections. Serum levels of acetaminophen, AST, ALT, LDH, ALP and bilirubin were recorded over a 24-hour period.

Results: Serum acetaminophen levels were similar between the groups. The AST, ALT, ALP, LDH, total bilirubin and direct bilirubin levels of Group A were significantly higher compared with the Group C, Group F1, Group F2 and Group F3. There was not a statistically significant difference in the AST, ALT, ALP, LDH, total bilirubin or direct bilirubin levels of the flumazenil-administered groups.

Conclusion: Flumazenil's prevention of the acetaminophen-induced increase in liver enzymes is promising. There is some indication that flumazenil could be used in treatment of acetaminophen intoxication (Tab. 2, Ref. 25). Full Text in PDF www.elis.sk.

Key words: flumazenil, acetaminophen, hepatotoxicity.
\end{abstract}

Acetaminophen (APAP) toxicity is the most common cause of acute poisoning in the US and Europe (1). APAP is a derivation of p-aminophenol, which is a synthetic non-opioid (2). In therapeutic doses, $8-10 \%$ of APAP converts to its reactive metabolite $\mathrm{N}$-acetyl benzoquinone (NAPQI). This metabolite is responsible for APAP's hepatic toxicity (2). NAPQI can form covalent bonds with cellular proteins and thereby modify their structure and function (3).

Severe hepatic failure occurs in $4 \%$ of the patients who take APAP in toxic doses. Less than half of these cases result in death or liver transplantation (4). Currently, $\mathrm{N}$-acetylcysteine (NAC), a

${ }^{1}$ Department of Anesthesiology, Erciyes University Medical Faculty, Kayseri, Turkey, and ${ }^{2}$ Department of Biochemistry, Erciyes University Medical Faculty, Kayseri, Turkey

Address for correspondence: R. Aksu, Hürriyet Mah. Mevlana Cad. Yalintas Apt. 20/8 38050 Melikgazi, Kayseri, Turkey. Phone: +90.352 .4374901 , Fax: +90.352 .4377333$

Acknowledgement: This work was supported by Research Fund of the Erciyes University. Project Number: B526. This study was presented at the Annual Congress of the Turkish Anaesthesiology and Intensive Care Society, Antalya, September 29-October 1, 2008. glutathione precursor, is the antidote for acetaminophen overdose (5). Although NAC is the first drug of choice for APAP overdose, it is associated with a variety of adverse effects (anaphylactic reaction, nausea, vomiting and diarrhea) $(6,7)$. NAC is also not entirely protective for APAP toxicity (8). NAC and methionine is not recommended in patients with hepatic failure symptoms because these symptoms increase hepatic encephalopathy (7). Therefore, other agents should be examined for their effectiveness (8).

GABA receptors take part in the conduction of antinociceptive impulses $(9-12)$. Flumazenil, as a derivate of 1,4-imidazodiazepine, is an antagonist of benzodiazepines with partial agonist properties (13). In previous study, Flumazenil was shown to be able to antagonize the acetaminophen-related antinociceptive effect (14). These studies examined flumazenil's potential beneficial contribution to the reduction of APAP hepatotoxicity.

\section{Material and method}

\section{Experiment animals}

After its approval by the Institutional Animal Use and Care Committee of the University of Erciyes Medical Faculty, this 
study was performed in 49 adult albino Wistar rats (weight 250 $-350 \mathrm{~g}$ ). The study procedures were carried out according to the ethical guidelines of the EEC ethical regulations for animal research (European Economic Community Council 86/609; D.L. 27/01/1992, No, 116).

The rats were housed in plastic cages, eight per cage, with free access to rat food (Aytekinler, Konya, Turkey) and tap water, and maintained on a 12-hour dark/light cycle (lights on at 7:00 AM) under controlled environmental conditions (temperature: $20{ }^{\circ} \mathrm{C}$, humidity: $4-50 \%$ ).

\section{Experimental groups and drug doses used}

Acetaminophen (Parol tablet, Atabay, Turkey) was administered in a dose of $3 \mathrm{~g} / \mathrm{kg}$ by means of a gastric catheter in $3 \mathrm{ml} \mathrm{sa}-$ line (15). Flumazenil (Anexate, Roche) was administered in doses of $0.1 \mathrm{mg} / \mathrm{kg}, 1 \mathrm{mg} / \mathrm{kg}$ and $10 \mathrm{mg} / \mathrm{kg}$ intraperitoneally (IP) (16).

A preliminary study with nine rats was carried out with the aim of deciding when to study liver functions following acetaminophen administration. In this study, rats were randomly divided into three groups. After all groups had been given $3 \mathrm{~g} / \mathrm{kg}$ of acetaminophen by means of a gastric catheter, the serum acetaminophen, AST, ALT, ALP and bilirubin levels were studied at 4, 24 and 40 hours. APAP levels were found to reach a peak at 4 hours. Liver function tests were found to reach a peak at 24 hours.

In the main experimental part of the study, the 40 rats used were randomly divided into five groups with eight rats in each. Drug doses were calculated after their weights were measured. Rats were acclimated to the environment before initiation of any procedure. Acetaminophen in tablet form was powdered in a case, diluted with saline (total volume for each rat equaling $3 \mathrm{ml}$ ) and administered intragastrically by means of a gastric catheter. Blood samples were obtained at 24 hours.

Rats in Control Group (Group C, $\mathrm{n}=8$ ) were given $3 \mathrm{ml}$ of saline solution $(0.9 \% \mathrm{NaCl})$ intragastrically by way of a gastric catheter. Rats in Acetaminophen Group (Group A, $\mathrm{n}=8$ ) were given $3 \mathrm{~g} / \mathrm{kg}$ of acetaminophen intragastrically. Rats in Experimental Group F1 (Group F1, $\mathrm{n}=8$ ) were given $3 \mathrm{~g} / \mathrm{kg}$ of acetaminophen intragastrically and one hour later were given $0.1 \mathrm{mg} /$ $\mathrm{kg}$ of Flumazenil IP. Rats in Experimental Group F2 (Group F2, $\mathrm{n}=8$ ) were given $3 \mathrm{~g} / \mathrm{kg}$ of acetaminophen intragastrically and, one hour later, $1 \mathrm{mg} / \mathrm{kg}$ of Flumazenil IP. Rats in Experimental Group F3 (Group F3, $\mathrm{n}=8$ ) were given $3 \mathrm{~g} / \mathrm{kg}$ of acetaminophen intragastrically and, one hour later, $10 \mathrm{mg} / \mathrm{kg}$ of Flumazenil IP.

Rats were sedated using $50 \mathrm{mg} / \mathrm{kg}$ of ketamine and $10 \mathrm{mg} /$ $\mathrm{kg}$ of xyilazine via an IP route 24 hours following acetaminophen administration. Intracardiac blood samples were obtained. Rats were sacrificed by the cervical dislocation method just after blood was drawn.

The obtained blood samples were immediately centrifuged in 5000 cycles for five minutes, and serum and plasma were separated. Serum and plasma were stored at $+4{ }^{\circ} \mathrm{C}$ until transportation to the laboratory. The serum Aspartate aminotransferase (AST), alanine aminotransferase (ALT), alkaline phosphatase (ALP), lactate dehydrogenase (LDH), total and direct bilirubin (TB, DB) levels were measured using a Cobas Integra 800 analyzer (Cobas
Reagents, Roche Diagnostics GmbH, D-68298 Mannheim). Plasma acetaminophen levels were measured with a Cobas Integra 400 analyzer (Cobas Reagents, Roche Diagnostics GmbH, D-68298 Mannheim) using aryl acylamidase with an enzymatic method.

\section{Statistical analysis}

Statistical analysis of the study was performed using SPSS software, version 15.0 (SPSS, Inc., Chicago, Illinois). The data distribution was assessed by way of the Kolmogorov-Smirnov test.

One-way ANOVA was used in the inter-group comparison of data with normal distribution. Statistical significance was determined by the post hoc Tukey HSD test. The data obtained were reported as means (SD). Kruskal-Wallis test was used in intergroup comparison of data without normal distribution. Bonferroni correction was performed by making cross-comparisons in cases of statistical significance. The obtained data were reported as median (min-max). p values $<0.05$ were considered statistically significant.

\section{Results}

In our preliminary study, the acetaminophen level was found to reach a peak at four hours and the AST, ALT, ALP, LDH levels were found to reach a peak at 24 hours (Tab. 1).

Statistically significant differences were found between groups in the observed values of AST ( $<<0.001)$, ALT $(p<0.001)$, ALP $(p=0.001), \operatorname{LDH}(p=0.001)$, TB $(p=0.001)$ and DB $(p=0.003)$ (Tab. 2).

The AST, ALT, LDH values were found to be significantly higher in Group A compared with the Control Group and with the Experimental groups (Group F1, Group F2, Group F3) (p $=0.001$ ). Although the AST, ALT, LDH values measured in the three groups for which flumazenil was administered following acetaminophen (Group F1, Group F2, Group F3) were found to be higher compared with the values measured in Group C, this difference was not statistically significant in paired comparisons (after Bonferroni correction) $(\mathrm{p}>0.05)$ (Tab. 2). However, the AST, ALT, LDH levels were found to be higher in one rat that was given $0.1 \mathrm{mg} / \mathrm{kg}$ of flumazenil and in one rat that was given $1 \mathrm{mg} / \mathrm{kg}$ of flumazenil (Tab. 2).

The ALP values were significantly lower in Group A than in the other groups $(p<0.05)$. There were no statistically significant differences between Group C, Group F1, Group F2 and Group F3 in terms of their ALP values ( $p>0.05)$ (Tab. 2).

Tab. 1. Liver Function Tests and Plasma Acetaminophen Levels (APAP) at 4, 24 and 40 hours.

\begin{tabular}{lccc}
\hline & $\begin{array}{c}\text { Group P4 } \\
(\mathrm{n}=3) \\
(\text { mean })\end{array}$ & $\begin{array}{c}\text { Group P24 } \\
(\mathrm{n}=3) \\
(\mathrm{mean})\end{array}$ & $\begin{array}{c}\text { Group P40 } \\
(\mathrm{n}=3) \\
(\mathrm{mean})\end{array}$ \\
\hline AST (IU/L) & 118.66 & 11585.33 & 3113.00 \\
ALT (IU/L) & 41.66 & 8889.33 & 3099.33 \\
ALP $(\mathrm{IU} / \mathrm{L})$ & 92.00 & 288.00 & 176.00 \\
LDH $(\mathrm{IU} / \mathrm{L})$ & 836.33 & 17525.00 & 657.33 \\
Total Bilirubin $(\mathrm{mg} / \mathrm{dl})$ & 0.73 & 0.55 & 0.46 \\
Direct Bilirubin $(\mathrm{mg} / \mathrm{dl})$ & 0.24 & 0.10 & 0.20 \\
APAP level $(\mu \mathrm{g} / \mathrm{ml})$ & 491.53 & 22.75 & 0.46 \\
\hline
\end{tabular}


Tab. 2. Plasma AST, ALT, ALP, LDH, Total Bilirubin, Direct Bilirubin and Plasma Acetaminophen Levels (APAP) in groups.

\begin{tabular}{|c|c|c|c|c|c|c|}
\hline & $\begin{array}{c}\text { Group C } \\
(\mathrm{n}=8) \\
(\mathrm{mean} \pm \mathrm{SD})\end{array}$ & $\begin{array}{c}\text { Group A } \\
(\mathrm{n}=8) \\
(\mathrm{mean} \pm \mathrm{SD})\end{array}$ & $\begin{array}{c}\text { Group F1 } \\
(\mathrm{n}=8) \\
(\mathrm{mean} \pm \mathrm{SD})\end{array}$ & $\begin{array}{c}\text { Group F } 2 \\
(\mathrm{n}=8) \\
(\mathrm{mean} \pm \mathrm{SD})\end{array}$ & $\begin{array}{c}\text { Group F3 } \\
(\mathrm{n}=8) \\
(\mathrm{mean} \pm \mathrm{SD})\end{array}$ & $\mathrm{p}$ \\
\hline$\overline{\mathrm{AST}(\mathrm{IU} / \mathrm{L})}$ & $78.0 \pm 19.4$ & $5966.5 \pm 5260.3^{*}$ & $340.6 \pm 667.0 \ddagger$ & $277.3 \pm 516.7 \ddagger$ & $216.6 \pm 144.2 \ddagger$ & $<0.001$ \\
\hline ALT (IU/L) & $67.1 \pm 10.7$ & $6292.0 \pm 4906.7^{*}$ & $397.3 \pm 838.9$ & $266.1 \pm 481.3^{\top}$ & $206.3 \pm 180.9$ & $<0.001$ \\
\hline ALP (IU/L) & $365.1 \pm 123.5$ & $188.3 \pm 51.2 *$ & $358.2 \pm 75.0$ & $380.8 \pm 99.6$ & $322.6 \pm 86.4$ & 0.001 \\
\hline LDH (IU/L) & $129.6 \pm 63.9$ & $10649 \pm 10977^{*}$ & $300.5 \pm 392.2$ & $223.6 \pm 179.1$ & $192.5 \pm 139.7$ & 0.001 \\
\hline $\begin{array}{l}\text { Total Biluribine } \\
(\mathrm{mg} / \mathrm{dl})\end{array}$ & $0.2 \pm 0.0$ & $0.9 \pm 0.6^{*}$ & $0.3 \pm 0.1$ & $0.4 \pm 0.1$ & $0.2 \pm 0.0$ & 0.001 \\
\hline $\begin{array}{l}\text { Direct Bilirubin } \\
(\mathrm{mg} / \mathrm{dl})\end{array}$ & $0.0 \pm 0.0$ & $0.3 \pm 0.3 * *$ & $0.0 \pm 0.0$ & $0.1 \pm 0.1$ & $0.0 \pm 0.0$ & 0.003 \\
\hline $\begin{array}{l}\text { APAP level } \\
(\mu \mathrm{g} / \mathrm{ml})\end{array}$ & $0.0 \pm 0.0$ & $73.8 \pm 55.6$ & $70.8 \pm 37.5$ & $35.1 \pm 33.8$ & $59.6 \pm 34.9$ & $0.251 \&$ \\
\hline
\end{tabular}

$* \mathrm{p}<0.05$ compared with Group C, Group F1, GroupF2, GroupF3, $\$$ p $<0.05$ compared with Group C, ** p $<0.05$ compared with GroupC, GroupF1, GroupF3, \& Comparison of Group A, Group F1, Group F2 and Group F3, Group C: Received $3 \mathrm{ml}$ of saline; Group A; Received $3 \mathrm{~g} / \mathrm{kg}$ of acetaminophen; Group F1; Received $3 \mathrm{~g} / \mathrm{kg}$ of acetaminophen and $0.1 \mathrm{mg} / \mathrm{kg}$ of flumazenil; Group F2; Received $3 \mathrm{~g} / \mathrm{kg}$ of acetaminophen and $1 \mathrm{mg} / \mathrm{kg}$ of flumazenil; Group F3; Received $3 \mathrm{~g} / \mathrm{kg}$ of acetaminophen and $10 \mathrm{mg} / \mathrm{kg}$ of flumazenil.

TB $(p=0.001)$ and DB $(p=0.003)$ values measured in Group A were significantly higher compared with the Control Group and the Experimental groups (Tab. 2).

When serum acetaminophen levels were compared, there was no statistically significant difference between Group A, Group F1, Group F2 and Group F3 (p=0.251) (Tab. 2).

\section{Discussion}

Acetaminophen is considered to be a predictable hepatotoxin, for which biochemical signs of liver damage will become apparent within 24 to 48 hours after the time of overdose. This hepatotoxin produces a dose-related centrilobular necrosis in the liver $(3,17)$. Grypioti et al $(18)$ reported that the elevated serum levels of hepatic AST, ALT (indicative of necrosis) and ALP (indicative of cholestasis) activities are in good agreement with the first wave of liver injury observed between 20 and $40 \mathrm{~h}$, and are due to the direct action of APAP on hepatocytes.

In our preliminary study, liver enzymes were found to reach a peak at 24 hours following APAP administration.

Schmidt and Dalhoff(19) reported that ALT levels above 1000 U/L were reached in all patients who had taken high dose acetaminophen. Grypioti et al (18) reported that ALT, AST and ALP values increased and that the liver changed histopathologically (grade of inflammation and apoptosis). They observed in their rat model that hepatic injury was generated with a toxic dose $(3.5 \mathrm{~g} /$ $\mathrm{kg}$ ) of acetaminophen. Iwalokun et al (20) administered a dose of $300 \mathrm{mg} / \mathrm{kg}$ of acetaminophen to mice via IP route for seven days and reported significant increases in AST, ALT, LDH, ALP, TB, and DB levels in the acetaminophen group compared with the control group.

In our study, although significant increases were found in serum AST, ALT, LDH, T.Bil and D.Bil levels in rats given $3 \mathrm{~g} / \mathrm{kg}$ of acetaminophen compared with the Control group, a significant difference was not found in serum ALP values.

APAP hepatotoxicity due to overdose is the most frequent cause of fulminant liver failure, with a mortality rate up to $90 \%$.
However, initiating the treatment in early stage in a good institution and performing liver transplantation in required cases decreases this frequency of mortality (21). Research on the prevention of high dose acetaminophen-induced hepatotoxicity is currently ongoing.

Reports by others have shown that certain agents were beneficial for reducing APAP hepatotoxicity (ribose cysteine, L-cysteine glutathione mixed disulfides and antioxidants). However, all these compounds were observed to be successful in reducing APAP hepatic toxicity only when administered prior to APAP exposure $(22-24)$. Very few agents have been reported to reduce APAP hepatotoxicity when administered after APAP exposure in the manner of an antidote (NAC, S-adenosyl-L-methionine) (25). NAC is the current clinical treatment for APAP overdose (25). However, NAC is effective only for patients who present within hours of an acute overdose and is less effective for late-presenting patients (5).

Terneus et al (25) compared NAC and SAM (S-adenosyl-Lmethionine) use on liver functions following high dose APAP and reported that both agents showed decreased liver enzymes but had not reached the levels of the control group. In our study, it was found that $10 \mathrm{mg} / \mathrm{kg}$ of IP flumazenil slowed the increase in liver enzymes that was related to high dose APAP hepatotoxicity better when compared to administration of $0.1 \mathrm{mg} / \mathrm{kg}$ and $1 \mathrm{mg} / \mathrm{kg}$ of flumazenil. However, this decrease was not statistically significant. The decrease in liver enzymes in one rat in the Flumazenil $0.1 \mathrm{mg} / \mathrm{kg}$ group and in one rat in the Flumazenil $1 \mathrm{mg} / \mathrm{kg}$ group did not recede to the levels in the other rats.

Madenoglu et al (14) reported that flumazenil antagonized the antinociceptive effect of acetaminophen in rats. However, this study proposed that flumazenil caused an analgesic effect by using GABA receptors because the mechanism of action of paracetamol has not been fully understood. Although flumazenil can have an effect on these receptors, another possible mechanism is that of flumazenil's metabolization by conversion to inactivated free carboxylic acid and glucoronic acid. Eighty percent of acetaminophen is excreted from the kidney as inactivated compounds conjugated with sulfuric acid and glucuronic acid. Because an increased glucuronic acid amount related to flumazenil indicates that more 
acetaminophen has become inactivated, a decrease in the amount going to the oxidase system resulting in NAPQI generation and a decrease in hepatotoxic effects are possible. However, histopathological studies at receptor and cellular levels are needed to understand these mechanisms of action.

In conclusion, our study is the first to compare the effectiveness of different doses of flumazenil in saline solution as an antidote for APAP toxicity. The effects at 24 hours of the administration of $0.1 \mathrm{mg} / \mathrm{kg}, 1 \mathrm{mg} / \mathrm{kg}$ and $10 \mathrm{mg} / \mathrm{kg}$ IP flumazenil one hour after the administration of intragastric APAP on levels of AST, ALT, LDH, total bilirubin and direct bilirubin were found to be similar to the levels for those cases in which APAP was not given. These results suggest that flumazenil, at least in our model, has some potential as an antidote for APAP toxicity.

\section{References}

1. Lee Wm. Acetaminophen and the U.S. Acute Liver Failure Study Group: lowering the risks of hepatic failure. Hepatology 2004; 40: 6-9.

2. Graham GG, Scott KF. Mechanism of action of paracetamol. Am J Ther 2005; 12: 46 - 55 .

3. Lee WM. Drug-induced hepatotoxicity. New Engl J Med 1995; 333 : $1118-1127$.

4. Simmons DL, Botting RM, Hla T. Cyclooxygenase isozymes: the biology of prostaglandin synthesis and inhibition. Pharmacol Rev 2004; 56: $387-437$.

5. Yang R, Miki K, He X, Killeen ME, Fink MP. Prolonged treatment with $\mathrm{N}$-acetylcystine delays liver recovery from acetaminophen hepatotoxicity. Crit are 2009; 13: R55.

6. Kao LW, Kirk MA, Furbee RB, Mehta NH, Skinner JR, Brizendine EJ. What is the rate of adverse events after oral $\mathrm{N}$-acetylcysteine administered by the intravenous route to patients with suspected acetaminophen poisoning? Ann Emerg Med 2003; 42: 741 - 750.

7. Flanagan RJ, Meredith TJ. Use of N-acetylcysteine in clinical toxicology. Am Med J 1991; 91 (3C): 131S - 139S.

8. Terneus MV, Kiningham KK, Carpenter AB, Sullivan SB, Valentovic MA. Comparison of S-Adenosyl-L-methionine and N-acetylcysteine protective effects on acetaminophen hepatic toxicity. J Pharmacol Exp Ther 2007; 320: 99 - 107.

9. Brogden RN, Goa KL. Flumazenil. A preliminary review of its benzodiazepine antagonist properties, intrinsic activity and therapeutic use. Drugs 1988; 35: 448 - 467.

10. Nishiayama T, Gyermek L, Lee, Kawasaki-Yatsugi S, Yamaguchi T. Synergistic analgesic effects of intrathecal midazolam and NMDA or AMPA receptor antagonists in rats. Can J Anaesth 2001; 48: $288-294$.
11. Holman JR Jr, Jing X, Sloan JW, Wala EP. The effects of flumazenil on the antinociceptive actions of morphine in rats. Receptors Channels 2003; 9: $325-328$.

12. Palaoglu O, Ayhan IH. The possible role of benzodiazepine receptors in morphine analgesia. Pharmacol Biochem Behav 1986; 25: 215 - 217.

13. Malan TP, Mata HP, Porreca F. Spinal GABA(A) and GABA(B) receptor pharmacology in a rat model of neuropathic pain. Anesthesiology 2002; 96: $1161-1167$.

14. Madenoglu H, Kacmaz M, Aksu R, Bicer C, Yaba G, Yildiz K, Dogru K, Boyaci A. The effects of naloxone and flumazenil on antinociceptive action of paracetamol in rats. Curr Ther Res 2010; 71: 111-117.

15. Tuntaterdtum S, Chaudhary IP, Cibull M, Robertson LW, Blouin RA. Acetaminophen hepatotoxicity: influence of phenobarbital and betanaphthoflavone treatment in obese and lean Zucker rats. Toxicol Appl Pharmacol 1993; 123: $219-225$.

16. Savic MM, Obradovic DI, Ugresic ND, Cook JM, Yin W, Bokonjic DR. Bidirectional effects of benzodiazepine binding site ligands in the elevated plus-maze: differential antagonism by flumazenil and beta-CCt. Pharmacol Biochem Behav 2004; 79: 279 - 290.

17. Black M. Acetaminophen hepatotoxicity. Gastroenterology 1980; 78 : $382-392$.

18. Grypioti AD, Theocharis SE, Papadimas GK, Demopoulos CA, Papapoulos-Daifoti Z, Basayiannis AC, Mykoniatis MG. Platelet-activating factor (PAF) involvement in acetaminophen-induced liver toxicity and regeneration. Arch Toxicol 2005; 79: 466 - 474.

19. Schmidt LE, Dalhoff K. Alpha-fetoprotein is a predictor of outcome in acetaminophen-induced liver injury. Hepatology 2005; 41: 26 - 31 .

20. Iwalokun BA, Efedede BU, Alabi-Sofunde JA, Oduala T, Magbagbeola $\mathrm{OA}$, Akinwande AI. Hepatoprotective and antioxidant activities of Vernonia amygdalina on acetaminophen-induced hepatic damage in mice. J Med Food 2006; 9: 524 - 530.

21. Makin A, Williams R. The current management of paracetamol overdosage. Brit J Clin Pract 1994; 48: 144 - 148.

22. Lucas AM, Hennig G, Dominick PK, Whiteley HE, Roberts JC, Cohen SD. Ribose cysteine protects against acetaminophen-induced hepatic and renal toxicity. Toxicol Pathol 2000; 28: $697-704$.

23. Berkeley LI, Cohen JF, Crankshaw DL, Shirota FN, Nagasawa HT. Hepatoprotection by L-cysteine-glutathione mixed disulfide, a sulfhydrylmodified prodrug of glutathione. J Biochem Mol Toxicol 2003; 17: 95 - 97.

24. Oz HS, McClain CJ, Nagasawa HT, Ray MB, de Villiers WJ, Chen TS. Diverse antioxidants protect against acetaminophen hepatotoxicity. J Biochem Mol Toxicol 2004; 18: 361 - 368.

25. Terneus MV, Brown JM, Carpenter AB, Valentovic MA. Comparison of S-adenosyl-L-methionine (SAMe) and N-acetylcysteine (NAC) protective effects on hepatic damage when administered after acetaminophen overdose. Toxicology 2008; 244: $25-34$. 